\title{
Proportion of Ophthalmic Self-Medication and Associated Factors among Adult Ophthalmic Patients Attending Borumeda Hospital, Dessie, Northeast Ethiopia
}

\author{
Nebiyat Feleke Adimassu (iD, ${ }^{1}$ Zemed Guchma Woldetsadik, ${ }^{2}$ and Haile Woretaw Alemu ${ }^{1}$ \\ ${ }^{1}$ Department of Optometry, School of Medicine, College of Medicine and Health Science, University of Gondar, Gondar, Ethiopia \\ ${ }^{2}$ Ophthalmology Department, Boru Meda Hospital, Dessie, Amhara, National Regional State, Ethiopia \\ Correspondence should be addressed to Nebiyat Feleke Adimassu; neby.uog@gmail.com
}

Received 14 October 2019; Revised 2 March 2020; Accepted 19 March 2020; Published 25 April 2020

Academic Editor: Antonio Queiros

Copyright (C) 2020 Nebiyat Feleke Adimassu et al. This is an open access article distributed under the Creative Commons Attribution License, which permits unrestricted use, distribution, and reproduction in any medium, provided the original work is properly cited.

Purpose. The aim of this study was to determine the proportion of ophthalmic self-medication and associated factors among adult ophthalmic patients attending Borumeda Hospital, Northeast Ethiopia, 2019. Methods. An institution-based cross-sectional study design was conducted on 402 participants at Borumeda Hospital from April 29 to May 24, 2019. Systematic random sampling technique was used to get study participants. Data were collected with a face-to-face interview by using a semistructured questionnaire. Data were entered into Epi Info 7 and analyzed by SPSS 20. Descriptive statistics and binary logistic regression analysis were employed. $P$ values of less than 0.05 were considered statistically significant. Results. The proportion of ophthalmic self-medication was 28.6\% (95\% CI; 24.6-33.3). Age-group 29-42 years (AOR: 2.19, 95\% CI: 1.06-4.52), absence of health insurance (AOR: 4.29; 2.35-7.84), more than 10 kilometer traveling distance to get eye services (AOR: $3.11 ; 1.58-6.12$ ), previous experience of ocular illness (AOR: 2.62, 95\% CI: 1.53-4.48), family or friend experience of ocular illness (AOR: 2.65, 95\%CI: 1.43-4.92), availability of ophthalmic medicine bottle/tube at home (AOR: 4.59, 95\% CI: 2.36-8.92), and poor knowledge about hazards of self-medication (AOR: 6.22; 3.26-11.85) were significantly associated with ophthalmic self-medication. Conclusion and Recommendations. The proportion of ophthalmic self-medication was high, which needs stakeholders' attention. The policymakers and regulatory body better to scale-up health insurance coverage, nearby accessible eye care services, improve knowledge of patients regarding the effect of ophthalmic self-medication, and proper disposal of leftover eye medication from the house. It is better to take regulatory actions on those who dispense ophthalmic medications without prescription.

\section{Introduction}

Self-medication is defined as selection and use of medicines by individuals to treat self-recognized illnesses or symptoms [1]. Ophthalmic self-medication is also defined as obtaining and consuming one or more medications without the advice of the eye care professional. This behavior includes purchasing drugs without a prescription, using leftover doses from previous prescriptions, and sharing drugs with other family members [2].

People practice ophthalmic self-medication for a variety of reasons. Ocular symptoms like redness, watering of the eye, foreign body sensation, and itching of the eye are common symptoms that initiate to use ophthalmic selfmedication. In addition to this, previous ocular illness, living far from the hospital, unaware and poor knowledge about hazards of self-medication, and simplifying their illness are among the factors for ophthalmic self-medication [2-6].

Globally, the prevalence of ophthalmic self-medication ranges from $25.6 \%$ to $73.6 \%$ [2-9]. The prevalence of selfmedication has sharply increased throughout the world. It is common practice in developing countries. Worldwide from all drugs purchased without any prescription, $80 \%$ accounted by developing countries [10]. In Ethiopia, eye diseases were common illnesses that lead to self-medication [11-15]. 
Self-medication practice is highly prone to irrational use of medications. The study showed that almost $90 \%$ of the ophthalmic self-medication was used inappropriately [2]. Possible consequences of improper administration of ophthalmic medication include microbial resistance, poor treatment outcome, adverse reactions, and disease progression, and finally may lead to visual morbidity $[7,16]$. When medications such as steroids are misused, they aggravate existing infections and may lead to blindness [17]. In addition, self-medication practice negatively affects healthcare-seeking behavior of individuals and causes delay in diagnosis of problems and appropriate treatments [15].

Even though various studies were conducted on selfmedication practices in different parts of Ethiopia, there was limited published evidence specifically on ophthalmic selfmedication practice and factors that influence it among ophthalmic patients.

Therefore, this study aimed to determine the proportion of ophthalmic self-medication practice and associated factors among adult ophthalmic patients attending Borumeda Hospital, Northeast Ethiopia. The result of this study will be important as a baseline for the researcher and a source of information for policymakers as well as eye health care provider for appropriate interventions to prevent the risks associated with self-medication practice.

\section{Methods}

2.1. Study Design, Setting, and Sampling. An institutionbased cross-sectional study was conducted to assess the proportion and associated factors of ophthalmic self-medication practice among adult ophthalmic patients attending Borumeda Hospital, Northeast Ethiopia, 2019.

The study was conducted at Borumeda Hospital from April 29 to May 24, 2019. Borumeda Hospital is found in Dessie town. Dessie town is located in $401 \mathrm{~km}$ far from Northeast of Addis Ababa, the capital city of Ethiopia. It has two public hospitals, four private hospitals, one private eye clinic, three government health centers, and thirty-six private clinics, and 56 drug retail outlets $[18,19]$.

Borumeda Hospital was established in 1955 G. C by Missionary to give ophthalmology and dermatology services. It has a catchment of approximately 2.5 million people according to the data obtained from the hospital office.

The secondary eye care unit has two ophthalmologists, five optometrists, one cataract surgeon, and two ophthalmic nurses. It provides comprehensive eye care services including major and minor ocular surgery, refraction service, and outpatient and inpatient service.

A total of 407 sample size was determined by a single proportional formula by considering $10 \%$ nonresponse rate. Then, a systematic random sampling method was used to select participants with a sampling fraction of three (every $3^{\text {rd }}$ individual).

The study was conducted in accordance with the Declaration of Helsinki and approved by the University of Gondar Ethical Review Board. In accordance with the Ethiopian National Research, Ethics Review Guideline, verbal informed consent was obtained from all adults older than 18 years using an information sheet in the local language "Amharic." Since the study did not involve invasive eye examination procedures, the university ethical review board approved verbal informed consent. Permission was obtained from Borumeda Hospital, and verbal consent was obtained from each study participants after explaining the purpose of the study. The interview was taken after the treatment. Participants got proper treatment whether they refused or agreed for the interview. They have the full right to participate and to refuse or withdraw at any time they want. Confidentiality of the information obtained was assured by coding and locking the data. Confidentiality was maintained during the data collection and analysis procedure.

The study participants' agreements were first obtained verbally prior to data collection. Then, the data were collected by trained senior optometrists who came from other institutions away from the hospital where the study was conducted.

All participants were informed about the adverse effect of using ophthalmic medication without consultation of the eye care professional.

\subsection{Definition of Ophthalmic Self-Medication}

2.2.1. Ophthalmic Self-Medication Practice. The participant who used one of the ophthalmic modern medicines at least once within the past two years for the specific ocular problem without consultation of eye care professionals [20].

2.2.2. Health Insurance. Participants who had health insurance from the government and those who had free medical services said to be health insured.

2.2.3. Distance to Get Eye Care Service. What is the traveling distance from residence to get eye care service? Participants who traveled more than ten kilometers to get eye care service were considered to be far, and the participants who travel ten kilometers or less were considered to be near [21].

2.2.4. Knowledge. Knowledge was determined based on ten knowledge questions and was graded as for its level (good and poor). The participant who answered correctly was given a score of one, and those did not answer correctly or did not know was given a score of zero. The total score was out of ten. A participant said to be having good knowledge if he/she answers $\geq 50 \%(\geq 5 / 10)$ of the question. Otherwise, it was considered as poor knowledge [13].

2.2.5. Housewife. A female who has husband, not employed by governmental and nongovernmental employers, who spent their time at home to keep house clean, cook foods, and take care of the child was considered as a housewife.

2.3. Data Collection. The pretested and structured questionnaire of local language "Amharic" was used to carry out an interview with adults older than 18 years ( $\mathrm{S} 1$ questioner). 
Regular check-up for completeness and consistency of the data was made on a daily basis. On the fieldwork, data quality was ensured through $5 \%$ on spot cross-checking of the sample at hospital by principal investigators. The collected data have been checked for accuracy and completeness by the principal investigators. The questioner included questions to assess sociodemographic factors, socioeconomic factors, healthcare-related factors, knowledge, and practice of ophthalmic self-medication.

2.4. Statistical Analysis. After coding, the data were entered into Epi Info version 7, exported, and analyzed by using SPSS version 20. Both descriptive and analytical methods were employed for analysis. Summary statistics, frequencies, and cross-tabulations were performed for the descriptive analysis of the data. Bivariable and multivariable logistic regression was used to determine the associated factors. The variables that were found with $P<0.2$ at bivariable logistic regression were entered to multivariable analysis. Variables were fitted into the model by using the enter method. The Hosmer and Lemeshow model fitness was used to check the model fitness of data. Multicollinearity between the independent variables was checked by the variance inflation factor. Adjusted odds ratio with a $95 \%$ confidence interval was used to show the strength of association. Those variables with a $P$ value less than 0.05 were considered as statistically significant.

\section{Results}

3.1. Sociodemographic Characteristics of the Study Participants. A total of 402 adults participated with a response rate of $98.7 \%$. The median age was 42 years with an interquartile range of 32 years. The majority $(245,60.9 \%)$ of the respondents were males. One hundred eight $(26.9 \%)$ of the respondents were in the age-group 18-28 years. One hundred thirty-four $(33.3 \%)$ of the population were unable to read and write (Table 1).

\subsection{Health Service and Previous Ocular History-Related} Characteristic of Study Participants. One hundred ninety-six $(48.8 \%)$ of the study participants had health insurance. Majority $300(74.6 \%)$ of the participants were traveled greater than ten $\mathrm{km}$ distance to get eye care services. One hundred sixty-five $(41.0 \%)$ of the participants had the previous history of eye illness and about 79 (19.7\%) of the participants had a positive history of family or friends ocular illness. Sixty-three (15.7\%) of participants had an eye medication bottle/tube at their own home. All participants heard about the hazards of self-medication and 321 (79.9\%) of participants had good knowledge about the hazards of self-medication.

3.3. Proportion of Ophthalmic Self-Medication Practice. The proportion of ophthalmic self-medication practice was 115 (28.6\%) (95\% CI: 24.6-33.3). Among them, 100 (87.0\%) did not know the name of the medication they had used and $95(82.6 \%)$ did not check the expiry date of the drug before
TABLE 1: Sociodemographic characteristics of the study participants attending Borumeda Hospital, Northeast Ethiopia, June 2019 $(n=402)$.

\begin{tabular}{|c|c|c|}
\hline Characteristic & Frequency & Percent \\
\hline \multicolumn{3}{|l|}{ Sex } \\
\hline Male & 245 & 60.9 \\
\hline Female & 157 & 39.1 \\
\hline \multicolumn{3}{|l|}{ Age (years) } \\
\hline $18-28$ & 108 & 26.9 \\
\hline $29-42$ & 101 & 25.1 \\
\hline $43-60$ & 100 & 24.9 \\
\hline$\geq 61$ & 93 & 23.1 \\
\hline \multicolumn{3}{|l|}{ Religion } \\
\hline Christian & 202 & 50.2 \\
\hline Muslim & 200 & 49.8 \\
\hline \multicolumn{3}{|l|}{ Residence } \\
\hline Urban & 213 & 53.0 \\
\hline Rural & 189 & 47.0 \\
\hline \multicolumn{3}{|l|}{ Marital status } \\
\hline Currently single & 112 & 27.9 \\
\hline Currently married & 290 & 72.1 \\
\hline \multicolumn{3}{|l|}{ Level of education } \\
\hline Unable to read and write & 134 & 33.3 \\
\hline Read and write only & 58 & 14.4 \\
\hline Primary education & 73 & 18.2 \\
\hline Secondary education & 53 & 13.2 \\
\hline College and above & 84 & 20.9 \\
\hline \multicolumn{3}{|l|}{ Type of occupation } \\
\hline Farmer & 162 & 40.3 \\
\hline Government employee & 50 & 12.4 \\
\hline Merchant & 66 & 16.4 \\
\hline Housewife & 39 & 9.7 \\
\hline Student & 42 & 10.5 \\
\hline Daily laborer & 31 & 7.7 \\
\hline Other* & 12 & 3.0 \\
\hline \multicolumn{3}{|c|}{ Family monthly income (ETB) } \\
\hline$\leq 720$ & 103 & 25.6 \\
\hline $721-965$ & 98 & 24.4 \\
\hline $966-3000$ & 111 & 27.6 \\
\hline$\geq 3001$ & 90 & 22.4 \\
\hline
\end{tabular}

${ }^{*}$ Work seekers and drivers.

they use it. Regarding the effects of the medication, the majority $(81,70.4 \%)$ of self-utilized participants did not improve from their illness, 20 (17.4\%) of participants improved from their illness, and 14 (12.2\%) of participants were worse their problem after self-medication.

3.4. Symptoms of Participants Triggered Ophthalmic SelfMedication. The common symptoms/illnesses that initiated for self-medication were redness, blurring of vision, and itching (Table 2).

3.5. Source of Ophthalmic Medicines for Self-Medication. The major sources of ophthalmic medicine for self-medication were pharmacy house $(83(72.2 \%))$, followed by leftover medication (20 (17.4\%)). The other source of medicine for ophthalmic self-medication was borrowing from friends or family $12(10.4 \%)$. 
TABLE 2: Symptoms of study participants for ophthalmic self-medication practice among study participants attending Borumeda Hospital, Northeast Ethiopia, June $2019(n=119)$.

\begin{tabular}{lcc}
\hline Symptoms & Frequency & Percent \\
\hline Redness & 47 & 39.5 \\
Blurring of vision & 29 & 24.4 \\
Itching & 26 & 21.8 \\
Foreign body sensation & 8 & 6.7 \\
Others* & 9 & 7.6 \\
\hline
\end{tabular}

*Burning sensation, swelling, and discharge.

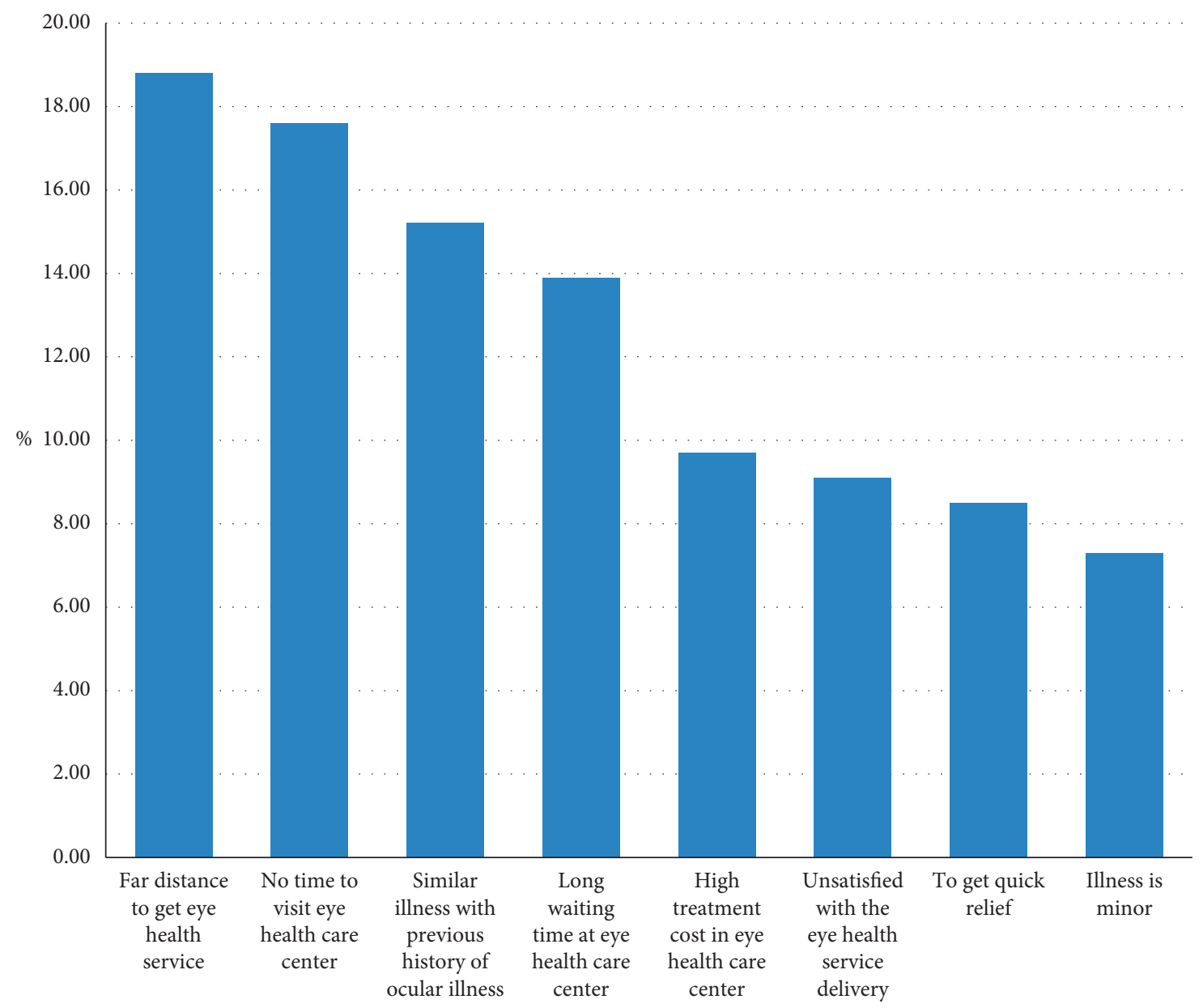

FIgURE 1: Reason of study participants for self-medication among adult ophthalmic patients attending Borumeda Hospital, Northeast Ethiopia, June 2019 ( $n=165)$.

3.6. Reasons for Self-Medication. The major reason for ophthalmic self-medication was the far distance to get eye health care service $(18.8 \%)$, followed by no time to visit at the eye health care center (17.6\%) (Figure 1).

3.7. Factors Associated with Ophthalmic Self-Medication Practice. Binary logistic regression analysis showing agegroup 29-42 years, absence of health insurance, previous history of ocular illness, family or friends experience of ocular illness, availability of eye medication bottle/tube at home, far traveling distance to get eye care services, and poor knowledge about self-medication were significant factors associated with ophthalmic self-medication practice.

Respondents of age-group 29-42 years were 2.19 times (AOR: 2.19, 95\% CI: 1.06, 4.52) more likely to practice ophthalmic self-medication than those of age-group 18-28 years.

Ophthalmic patients who did not have health insurance were more than four times (AOR: 4.29, 95\% CI: 2.35-7.84) more likely to practice self-medication than those who had health insurance. Ophthalmic patients who traveled more than ten $\mathrm{km}$ to get eye health services were nearly three (AOR: 3.11, 95\% CI: 1.58-6.12) times more likely to practice 
TABLE 3: Factors associated with ophthalmic self-medication among adult ophthalmic patients attending Borumeda Hospital, Northeast Ethiopia, June $2019(n=402)$.

\begin{tabular}{|c|c|c|c|c|}
\hline \multirow[t]{2}{*}{ Variables } & \multicolumn{2}{|c|}{$\begin{array}{l}\text { Ophthalmic self- } \\
\text { medication }\end{array}$} & \multirow[t]{2}{*}{ COR $(95 \% \mathrm{CI})$} & \multirow[t]{2}{*}{$\operatorname{AOR}(95 \% \mathrm{CI})$} \\
\hline & Yes & No & & \\
\hline \multicolumn{5}{|c|}{ Age-group (years) } \\
\hline $18-28$ & 25 & 83 & 1.00 & 1.00 \\
\hline $29-42$ & 35 & 66 & $1.76(0.96,3.22)$ & $2.19(1.06,4.52)^{*}$ \\
\hline $43-60$ & 34 & 66 & $1.71(0.93,3.14)$ & $1.69(0.80,3.57)$ \\
\hline$\geq 61$ & 21 & 72 & $0.96(0.50,1.87)$ & $0.89(0.38,2.09)$ \\
\hline \multicolumn{5}{|c|}{ Health insurance } \\
\hline No & 77 & 129 & $2.48(1.57,3.90)$ & $4.29(2.35,7.84)^{* * *}$ \\
\hline Yes & 38 & 158 & 1.00 & 1.00 \\
\hline \multicolumn{5}{|c|}{ Previous history of ocular illness } \\
\hline Yes & 67 & 98 & $2.69(1.72,4.19)$ & $2.62(1.53,4.48)^{* *}$ \\
\hline No & 48 & 189 & 1.00 & 1.00 \\
\hline \multicolumn{5}{|c|}{ Family or friends experience of ocular Illness } \\
\hline Yes & 39 & 40 & $3.16(1.90,5.28)$ & $2.65(1.43,4.92)^{* *}$ \\
\hline No & 76 & 247 & 1.00 & 1.00 \\
\hline \multicolumn{5}{|c|}{ Availability eye medication bottle/tube at home } \\
\hline Yes & 39 & 24 & $5.62(3.18,9.93)$ & $4.59(2.36,8.92)^{* * *}$ \\
\hline No & 76 & 263 & 1.00 & 1.00 \\
\hline \multicolumn{5}{|c|}{ Travel distance to get eye care services } \\
\hline Far & 94 & 206 & $1.76(1.02,3.01)$ & $3.11(1.58,6.12)^{* *}$ \\
\hline Near & 21 & 81 & 1.00 & 1.00 \\
\hline \multicolumn{5}{|l|}{ Knowledge } \\
\hline Poor & 44 & 37 & $4.18(2.51,6.97)$ & $6.22(3.26,11.85)^{* * *}$ \\
\hline Good & 71 & 250 & 1.00 & 1.00 \\
\hline
\end{tabular}

self-medication than those who traveled less than or equal to ten $\mathrm{km}$.

Ophthalmic patients with previous experience of ocular illness were more than two times (AOR: 2.62, 95\% CI: 1.53-4.48) more likely to practice ophthalmic self-medication than those without previous experience of ocular illness. Adult ophthalmic patients with family or friend experience of ocular illness were nearly three (AOR: 2.65, 95\% CI: 1.43-4.92) times more likely to practice self-medication than those without family or friend experience of ocular illness. Ophthalmic patients who had ophthalmic medication (bottle/tube) at home were more than four times (AOR: 4.59, 95\% CI: 2.36-8.92) more likely to practice self-medication than those who had not available ophthalmic medicines at home.

Adult ophthalmic patients who had poor knowledge about the hazards of self-medication were more than six (AOR: 6.22, 95\% CI: 3.26-11.85) times more likely to practice self-medication than those who had good knowledge (Table 3).

\section{Discussion}

In this study, the proportion of ophthalmic self-medication practice was $28.6 \%$ (95\% CI: 24.6, 33.3). This finding is in line with a study from Argentina (25.6\%) [20] and Colombia (25.7\%) [22]. This might be due to the similarity of target population in terms of age. These studies were carried on the adult population. They also considered modern ophthalmic medication use to define self-medication.
This finding is lower than the report from Tanzania (59.8\%) [5], Nigeria (73.6\%) [2], India (41.2\%) [23], and Brazil (40.5\%) [7]. This variation might be due to the difference in the target population in terms of age and the use of traditional medicine included as self-medication practice. The previous study done in Tanzania [5], India [23], and Brazil [7] included both traditional and modern medicine use as self-medication, while in this study only modern medicine was considered. In addition to this, the target population of the study done in Nigeria [2] and Brazil [7] covered all age-groups including the pediatric population, while this study included only adult population (age $>18$ years).

Regarding associated factors, respondents of age-group 29-42 years were more likely to practice self-medication than those of age-group 18-28 years. This might be due to eye diseases being more common in older people, and this could lead to ophthalmic medicines without consultation of eye-care providers [24].

Noninsured ophthalmic patients were more likely to practice self-medication than insured ophthalmic patients. This finding agrees with studies done in Ghana [6]. This might be due to the financial constraint that participants could not afford to pay all eye health services. In addition to this, having health insurance increase health care utilization, and this could reduce self-medication practice [25].

Ophthalmic patients who traveled a far distance to get eye health services were more likely to practice self-medication than those who traveled near distance. This might be 
due to inaccessibility of eye-care center around. In addition to this, it might be due to the financial constraint that participants might not afford transportation cost to come to the eye health center and may prefer to buy ophthalmic medicine from a nearby pharmacy.

Adult ophthalmic patients with a history of previous ocular illness were more likely to practice self-medication than patients without a previous history of ocular illness. This was supported by different studies [2,6]. This might be due to the similarity of symptoms of eye diseases patients believing that ocular medications taken previously can cure their current eye disease.

Ophthalmic patients who had ophthalmic medication bottle/tube at home were more likely to practice self-medication than those who had not available ophthalmic medicines at home. This might be due to the similarity of symptoms of eye diseases patients believing that ocular medications taken previously can cure their current eye disease.

Those study participants with positive family/friend history of ocular illness were more likely to practice ophthalmic self-medication than those who had no family/ friend history ocular illness. This might be due to the similarity of symptoms or illness leading to the use of similar ophthalmic medicine.

Adult ophthalmic patients who had poor knowledge about the hazards of self-medication were more likely to practice self-medication than those who had good knowledge. This finding was agreed with different studies $[13,22]$. This might be due to knowledgeable ophthalmic patients fearing the bad adverse reactions of improper use of medication.

Since optometrists participated for data collection, this study has social desirability bias.

The study also has a limitation of recall bias because ophthalmic self-medication is assessed based on the selfreport of the participants for their last two years of experiences. Income was not assessed by wealth index.

\section{Conclusion and Recommendations}

The proportion of ophthalmic self-medication was high, which needs stakeholders' attention. Absence of health insurance, history of previous ocular illness, family or friends experience of ocular illness, availability of eye medication bottle/tube at home, far-traveling distance to get eye care services, and poor knowledge about hazards of self-medication were significantly associated factors. The policymakers and regulatory body better to scale-up health insurance coverage, nearby accessible eye care services, improve knowledge of patients regarding the effect of ophthalmic self-medication, and proper disposal of leftover eye medication from the house. It is better to take regulatory actions on those who dispense ophthalmic medications without prescription.

\section{Data Availability}

All data required are available on the manuscript and will be supporting information.

\section{Conflicts of Interest}

The authors declare that they have no conflicts of interest.

\section{Authors' Contributions}

Zemed Guchma Woldetsadik, and Haile Woretaw Alemu contributed equally to this work.

\section{Acknowledgments}

The authors would like to thank the University of Gondar for allowing us to study this research by giving ethical approval. The authors are also very grateful to the study participants.

\section{References}

[1] Organization WHO, Guidelines for the Regulatory Assessment of Medicinal Products for Use in Self-Medication, World Health Organization, Geneva, Switzerland, 2000.

[2] I. A. Ajayi, O. J. Omotoye, K. O. Ajite, C. O. Fadamiro, and E. A. Ajayi, "Self medication practices among patients seen in A suburban tertiary eye care centre in Nigeria," Asian Journal of Medical Sciences, vol. 5, no. 2, pp. 85-90, 2014.

[3] T. Bisika, P. Courtright, R. Geneau, A. Kasote, L. Chimombo, and M. Chirambo, "Self treatment of eye diseases in Malawi," African Journal of Traditional, Complementary and Alternative Medicines, vol. 6, no. 1, 2010.

[4] R. Kadri, S. Hegde, A. A. Kudva, A. Achar, S. P. Shenoy, and I. J. B. M. Res, "Self-medication with over the counter ophthalmic preparations: is it safe?" International Journal of Biological and Medical Research, vol. 2, no. 2, pp. 528-530, 2011.

[5] G. Kagashe and B. Msela, "Self medication among patients seen at ophthalmology clinics at four hospitals in Dar es Salaam Tanzania," IOSR Journal of Pharmacy, vol. 2, no. 5, pp. 21-25, 2012.

[6] S. Kyei, S. Ocansey, E. K. Abu, and B. N. Gyedu, "Appraisal of the practice of ocular self-medication in cape coast metropolis, Ghana," Optometry Reports, vol. 4, no. 1, 2014.

[7] R. S. Carvalho, N. Kara-José, E. R. Temporini, N. Kara-Junior, and R. Noma-Campos, "Self-medication: initial treatments used by patients seen in an ophthalmologic emergency room," Clinics, vol. 64, no. 8, pp. 735-741, 2009.

[8] N. Gupta, P. Vashist, R. Tandon, S. K. Gupta, M. Kalaivani, and S. Dwivedi, "Use of traditional eye medicine and selfmedication in rural India: a population-based study," PloS One, vol. 12, no. 8, Article ID e0183461, 2017.

[9] S. N. Onwubiko, B. Eze, N. Udeh, O. Arinze, M. Okoloagu, and C. Chuka-Okosa, "Mapping the pathways to eye care in a rural south-east Nigerian population: any implications for practice, eye care programs and policy?" Rural \& Remote Health, vol. 14, no. 4, 2014.

[10] P. R. Gore and S. Madhavan, "Consumers' preference and willingness to pay for pharmacist counselling for non-prescription medicines," Journal of Clinical Pharmacy and Therapeutics, vol. 19, no. 1, pp. 17-25, 1994.

[11] S. A. Bekele, M. D. Argaw, and A. W. Yalew, "Magnitude and factors associated with self-medication practices among university students: the case of arsi university, college of health science, asella, Ethiopia: cross-sectional survey based study," OALib, vol. 3, no. 6, pp. 1-15, 2016. 
[12] T. Eticha and K. Mesfin, "Self-medication practices in mekelle, Ethiopia," PLoS One, vol. 9, no. 5, Article ID e97464, 2014.

[13] M. Shafie, M. Eyasu, K. Muzeyin, Y. Worku, and S. MartínAragón, "Prevalence and determinants of self-medication practice among selected households in Addis Ababa community," PLoS One, vol. 13, no. 3, Article ID e0194122, 2018.

[14] A. Baye and O. Sada, "Self-medication practice in community pharmacies: the case of Dessie town, Northeast Ethiopia," Advances in Pharmacoepidemiology and Drug Safety, vol. 7, no. 1, pp. 1-3, 2018.

[15] M. B. Ayalew, "Self-medication practice in Ethiopia: a systematic review," Patient Preference and Adherence, vol. 11, pp. 401-413, 2017.

[16] D. Limaye, V. Limaye, G. Krause, and G. Fortwengel, "A systematic review of the literature on survey questionnaires to assess self-medication practices," International Journal of Community Medicine and Public Health, vol. 4, 2017.

[17] R. Kadri, S. Hegde, A. A. Kudva, and A. Achar, "Over the counter ophthalmic drug misuse, are we aware?" Online Journal of Health and Allied Sciences, vol. 9, no. 2, 2010.

[18] G. Tefera and Y. Seid, "Actual practice of healthcare providers towards prevention and control of Multidrug-resistant tuberculosis (MDR-TB) at Borumeda Hospital, Ethiopia," African Journal of Pharmacy and Pharmacology, vol. 11, no. 12, pp. 152-160, 2017.

[19] A. Kebede and H. Gerensea, "Prevalence of needle stick injury and its associated factors among nurses working in public hospitals of Dessie town, Northeast Ethiopia," BMC Research Notes, vol. 11, no. 1, p. 413, 2018.

[20] G. E. Marquez, V. E. Torres, V. M. Sanchez et al., "Selfmedication in ophthalmology: a questionnaire-based study in an Argentinean population," Ophthalmic Epidemiology, vol. 19, no. 4, pp. 236-241, 2012.

[21] Federal Ministry of Health, "Health and health related indicator," in Policy Planning Directorate, pp. 59-63, Federal Ministry of Health, Abuja, Nigeria, 2016.

[22] G. E. Marquez, H. Piñeros-Heilbron, V. Sanchez, V. Torres, A. Gramajo, and C. Juarez, "Eye drop self-medication: comparative questionnaire-based study of two Latin American cities," Journal of Clinical \& Experimental Ophthalmologyl, vol. 5, no. 2, 2014.

[23] R. Gupta and P. Malhotra, "Self-medication in ophthalmology-a northern Indian tertiary hospital experience," International Journal of Basic and Clinical Pharmacology, vol. 5, no. 6, 2016.

[24] M. Khalaj, A. Barikani, and H. Ghasemi, "Eye disorders in old people," Global Journal of Health Science, vol. 5, no. 1, pp. 79-86, 2013.

[25] A. D. Mebratie, R. Sparrow, Z. Yilma, D. Abebaw, G. Alemu, and A. Bedi, "Impact of Ethiopian pilot community-based health insurance scheme on health-care utilisation: a household panel data analysis," The Lancet, vol. 381, p. S92, 2013. 